\title{
Fluorine effect on pericyclic and pseudopericyclic processes: Evidences and $a b$ initio theory ${ }^{\dagger}$
}

\author{
LAKSHMINARAYANAN AKILANDESWARI ${ }^{1,2}$, MADHAVAN JACCOB $^{1}$ and \\ PONNAMBALAM VENUVANALINGAM ${ }^{1, *}$ \\ ${ }^{1}$ School of Chemistry, Bharathidasan University, Tiruchirapalli 620024 \\ ${ }^{2}$ Present address: Department of Chemistry, Sri Sarada College for Women, Salem 636016 \\ e-mail: venuvanalingam $@$ yahoo.com
}

\begin{abstract}
Electrocyclic ring opening (ERO) reactions of 2-pyrone, 2-pyranol and pyran and their fluoro compounds (1-6) have been studied at MP2/6-31G(d) level with special emphasis on the influence of fluorine on these pericyclic/pseudopericyclic processes. Calculations clearly predict that substitution of fluorine at $\mathrm{C} 6$ favour the reaction both kinetically and thermodynamically. Magnetic susceptibility anisotropy $\left(\Delta \chi_{\text {aniso }}\right)$, NICS $(0), \mathrm{NBO}$ and bond critical property $(\mathrm{BCP})$ analyses clearly illustrate the following; 2-pyrone (1) and 6-fluoro-2-pyrone (2) reactions are pseudopericyclic; 6-fluoro-2-pyranol (reaction 4) corresponds to a borderline case; 2-pyranol (3) and pyran (5) and 6-fluoro pyran (6) reactions are clearly pericyclic in character. Correspondingly pseudeopericyclic reactions show up orbital disconnections and fluorine delays the occurrence of orbital disconnections on the reaction trajectory.
\end{abstract}

Keywords. Pericyclic reaction; pseudeopericyclic reaction; fluorine; NICS(0); orbital disconnections; NBO analysis.

\section{Introduction}

The concept of pseudeopericyclic reactions was introduced by Lemal ${ }^{1}$ and coworkers in 1976 as follows 'A pseudopericyclic reaction is a concerted transformation whose primary changes in bonding encompass a cyclic array of atoms, at one (or more) of which non-bonding and bonding atomic orbitals interchange roles. The role interchange means a "disconnection" in the cyclic array of overlapping orbitals because the atomic orbitals switching functions are mutually orthogonal'. After two decades, it was extensively studied by Birney and coworkers ${ }^{2-6}$ and they proposed that the pseudopericyclic reactions would have the following characteristics: Very low activation energies, nearly-planar transition states and symmetry allowedness. Later many methods based on the magnetic properties such as NICS ${ }^{7,8}$ ACID $^{9-12}$ have been developed to characterize pseudeopericyclic reactions. These methods were successfully used by Rodríguez Otero and their coworkers, ${ }^{13-19}$ to identify the nature of reactions as pericyclic or pseudopericyclic. Lopez and de Lera et $a l^{20}$ showed that pseudopericyclic reactions do not

\footnotetext{
${ }^{\dagger}$ Dedicated to the memory of the late Professor S K Rangarajan *For correspondence
}

show a maximum in ellipticity of the forming bond along the reaction coordinate. Recently ELF, $\mathrm{BCP}^{21-26}$ analyses have also been used to differentiate pericyclic reactions from pseudopericyclic reactions.

Electrocyclic ring opening (ERO) of pyrone has been found to be pseudeopericyclic by Birney and coworkers $^{27}$ and later Rodríguez and coworkers ${ }^{28}$ have confirmed this by using NBO analysis. $\mathrm{We}^{29-30}$ have studied the thermolysis of 2-pyrone and 6-halo-2pyrone and have found that fluorine substitution substantially altered the potential energy surface for ERO, sigmatropic rearrangement and electrocyclic ring closing (ERC) of pyrones. Fluorine is known to strongly perturb reaction barriers and mechanisms. ${ }^{31,32}$ This has motivated us to look at the pericyclic/ pseudeopericyclic character of ERO of a set of molecules having structures close to 2-pyrone and with fluorine substitution. Therefore ERO reactions of 2pyrone, 2-pyranol and pyran (figure 1) and their fluoro compounds (reactions 1-6) have been investigated with a view to bring out the role of fluorine in altering their pericyclic and pseudeopericyclic behaviours.

\section{Computational details}

Geometries of all species at stationary points in the potential energy surface have been calculated at 


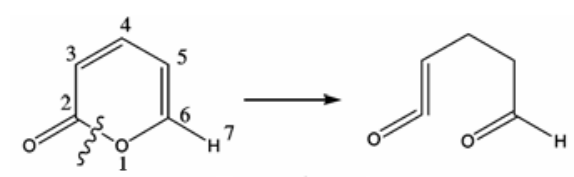

Reaction 1

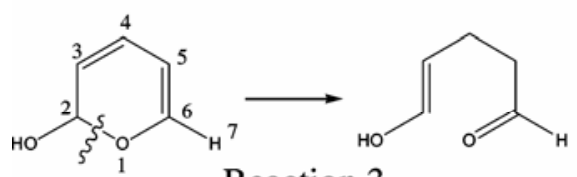
Reaction 3<smiles>COc1ccccc1</smiles>

Reaction 5<smiles>CCOC(=O)C=CCCC(=O)F</smiles>

Reaction 2

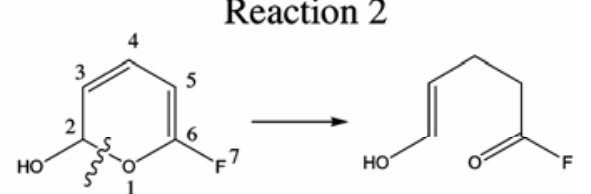

Reaction 4

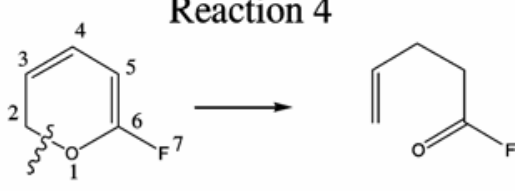

Reaction 6

Figure 1. Schematic representation of the reactions under study.

MP2/6-31G $(d)^{33}$ level. This method has been chosen as it has been found reliable in earlier reports ${ }^{22,34}$ and especially for thermolysis reactions. ${ }^{34}$ Stationary points have been characterized by computing vibrational frequencies; reactants, products have all real frequencies and TSs have one imaginary frequency. All calculations have been performed with Gaussian $98 \mathrm{~W}$ program. ${ }^{35}$ The free energies have been calculated at $298.15 \mathrm{~K}$ and $1 \mathrm{~atm}$ pressure. NBO calculations $^{36-38}$ have been done at MP2/6-31G(d) level. Also the whole path for each reaction was obtained using the intrinsic reaction coordinate (IRC) (I9-41 $^{39}$ with mass-weighted cartesian coordinates. Changes in magnetic properties along the IRC have been monitored at different points using the nucleusindependent chemical shift (NICS) and magnetic susceptibility anisotropy $\left(\chi_{\text {aniso }}\right)$. NICS $(0)$ values were obtained by using a slightly larger basis set in conjunction with the GIAO (Gauge-Independent Atomic Orbital) ${ }^{42}$ method. Magnetic susceptibility values were calculated by computing the NMR shielding tensors at the 6-311G $(2 d, p)$ level. This was calculated using the IGAIM ${ }^{43,44}$ method. TS1 could not be located at MP2/6-31G $(d)$ level and therefore IRC on TS 1 was performed at the $\mathrm{HF} / 6-31 \mathrm{G}(d)$ geometry and $\Delta \chi_{\text {aniso }}$ and $\operatorname{NICS}(0)$ values for reaction 1 have also been calculated on this geometry.

\section{Results and discussion}

\subsection{Energetics}

Figure 1 presents the electrocyclic ring opening reactions 1-6 considered here. Relative free energy profile of them is presented in figure 2 along with the optimized geometries of TS2-TS6 and selected bond parameters. It is important to mention that the TS 1 could not be located at MP2/6-31G(d) level. According to Birney et al, pseudopericyclic reactions have planar or nearly planar transition states and usually exhibit small reaction barrier. The small activation free energy $\left(\Delta G^{\ddagger}=6.82 \mathrm{kcal} \mathrm{mol}^{-1}\right)$ of the reaction 2 indicates its pseudopericyclic nature. Reactions 3 and 5 have larger free energy of activation $\left(\Delta G^{\ddagger}{ }_{\mathrm{ERO}}=20.66,20.62 \mathrm{kcal} \mathrm{mol}^{-1}\right.$ respectively) and this reveals pericyclic character of these reactions and all of them are endothermic. The moderate activation free energy barrier of the reactions 4 and 6 $\left(\Delta G^{\ddagger}{ }_{\mathrm{ERO}}=14.96,16.95 \mathrm{kcal} \mathrm{mol}^{-1}\right.$ respectively) indicates the decrease of pericyclic character and both of them are exothermic. Fluorine substitution reduces the pericyclic nature of the reactions 3 and 5 and increases the pseudopericyclic character through the participation of its lone pair during the ERO reaction. A careful examination of the TS geometries (figure 2) reveals the following: TS2 has nearly planar geometry indicating pseudopericyclic character. Geometries of TS4 and TS6 deviate from planarity proving them to be borderline cases. Structures of TS3 and TS5 are non-planar and it confirms the pericyclic character. Thermodynamic parameters are presented in table 1. $\Delta H^{\ddagger}$ values show the same trend as $\Delta G^{\ddagger}$ and $\Delta S^{\ddagger}$ values are characteristic of unimolecular reaction.

\subsection{Magnetic susceptibility anisotropy ( $\left.\Delta \chi_{\text {aniso }}\right)$}

Figure 3 shows the variation of relative magnetic susceptibility anisotropy $\left(\Delta \chi_{\text {aniso }}\right)$ along the reaction coordinate for reactions 1-6 under study. As men- 


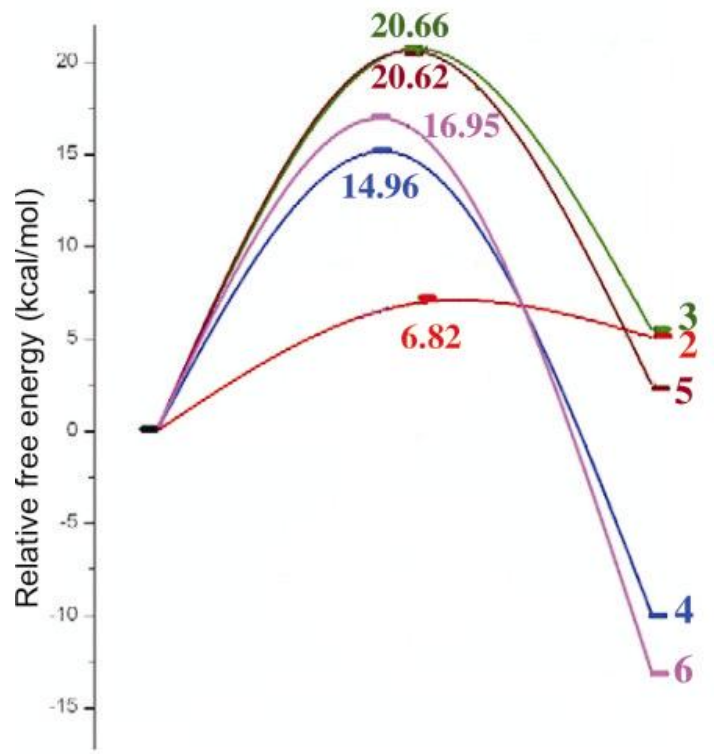

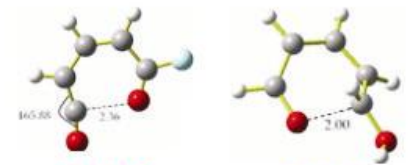

TS 2

Figure 2. Relative Free energy profile computed at MP2/6-31G $(d)$ level.

Table 1. Thermochemical parameters of the reactions 1-6 computed at MP2/6-31G(d) level.

\begin{tabular}{lcc}
\hline System & $\Delta H^{+}\left(\mathrm{kcal} \mathrm{mol}^{-1}\right)$ & $\Delta S^{\dagger}\left(\mathrm{cal}^{-1} \mathrm{~mol}^{-1}\right)$ \\
\hline 1 & $\#$ & $\#$ \\
2 & $7.27(0 \cdot 26)$ & $1.51(-4 \cdot 86)$ \\
3 & $20.75(12 \cdot 76)$ & $0.27(-7.92)$ \\
4 & $14.93(22 \cdot 12)$ & $-0.09(-8 \cdot 90)$ \\
5 & $20 \cdot 54(15 \cdot 58)$ & $-0.27(-8 \cdot 24)$ \\
6 & $16.51(26.83)$ & $-0.5(-9.23)$ \\
\hline
\end{tabular}

\#TS could not be located for reaction 1 at MP2/6-31 G(d) level

tioned in earlier reports, ${ }^{7,13-19}$ pseudopericyclic reactions do not show aromatic enhancement and consequently, no minima will occur in the $\Delta \chi_{\text {aniso }}$ profile near TS and this is because of the orbital disconnections in the cyclic overlap. $\Delta \chi_{\text {aniso }}$ profile of reactions 1 and 2 show a small maximum instead of a minimum reflecting pseudopericyclic character. It is further noted that substitution of fluorine have significantly reduced the $\Delta \chi_{\text {aniso }}$ values along the reaction coordinate for reactions 4 and 6 . As can be seen from figure 3, reactions 3,5 and 6 exhibit a shallow minimum near the transition state, indicating enhancement of aromatic character proving them to be pericyclic. In the case of reaction 4 , neither minima nor maxima observed near the transition state and this indicates it to be a borderline case. Overall the fluorine substitution doesn't seem to affect $\Delta \chi_{\text {aniso }}$ values of the pseudopericyclic reactions while it decreases the $\Delta \chi_{\text {aniso }}$ values of the pericyclic reactions.

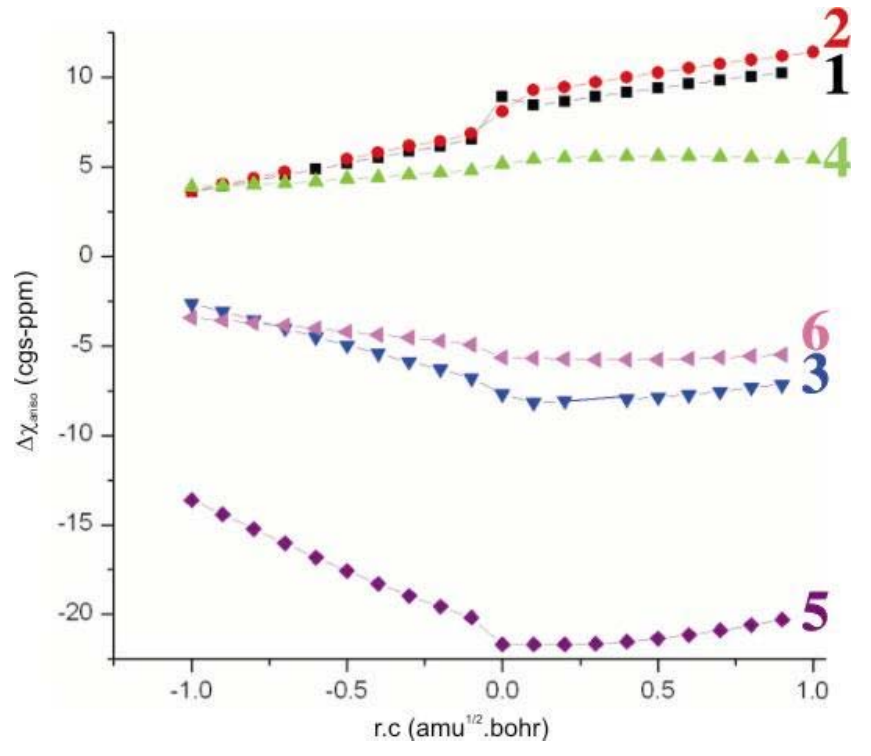

Figure 3. Variation of relative magnetic susceptibility anisotropy along the reaction coordinates.

\subsection{NICS}

Variation in NICS (0) along the reaction coordinate is shown in figure 4 . The NICS (0) profile gives the measure of aromaticity of the species on the reaction trajectory and pericyclic reactions show minima near the TS indicative of aromatic enhancement. Reactions 1 and 2 exhibit a maxima near the transition state instead of minima, confirming to pseudopericyclic character. Reactions 3, 5 and 6 exhibit a shallow minimum near the transition state and this 
Table 2. Wiberg bond orders of selected bonds computed at MP2/6-31G $(d)$ level.

\begin{tabular}{lcccccc}
\hline & TS 1* & TS 2 & TS 3 & TS 4 & TS 5 & TS 6 \\
\hline O1-C2 & 0.2220 & 0.2237 & 0.2631 & 0.3234 & 0.3068 & 0.3641 \\
C2-C3 & 1.4204 & 1.4263 & 1.3376 & 1.2321 & 1.4486 & 1.3448 \\
C3-C4 & 1.2806 & 1.2947 & 1.4422 & 1.5356 & 1.3884 & 1.4582 \\
C4-C5 & 1.5534 & 1.5278 & 1.3864 & 1.3018 & 1.4400 & 1.3691 \\
C5-C6 & 1.2301 & 1.2321 & 1.3390 & 1.3819 & 1.3057 & 1.3382 \\
C6-O1 & 1.5127 & 1.4885 & 1.4242 & 1.3486 & 1.4561 & 1.3815 \\
C2-O7 & 1.9511 & 1.9327 & - & - & - & - \\
\hline
\end{tabular}

*The geometry has been obtained at $\mathrm{HF} / 6-31 \mathrm{G}(d)$ level

Table 3. Major NLMO contribution for the forming bond at MP2/6-31G $(d)$ level.

\begin{tabular}{lcccccc}
\hline & TS 1 & TS 2 & TS 3 & TS 4 & TS 5 & TS 6 \\
\hline NLMO & LP O1 & LP O1 & LP O1 & $\begin{array}{c}\text { \% O1-C2 } \\
\text { LP O1 }\end{array}$ & LP O1 & $\#$ \\
BO & $0 \cdot 105$ & 0.103 & 0.0884 & $\begin{array}{l}0.2121 \\
0.0469\end{array}$ & 0.0894 & $\#$
\end{tabular}

It could not be located at MP2/6-31G $(d)$ level

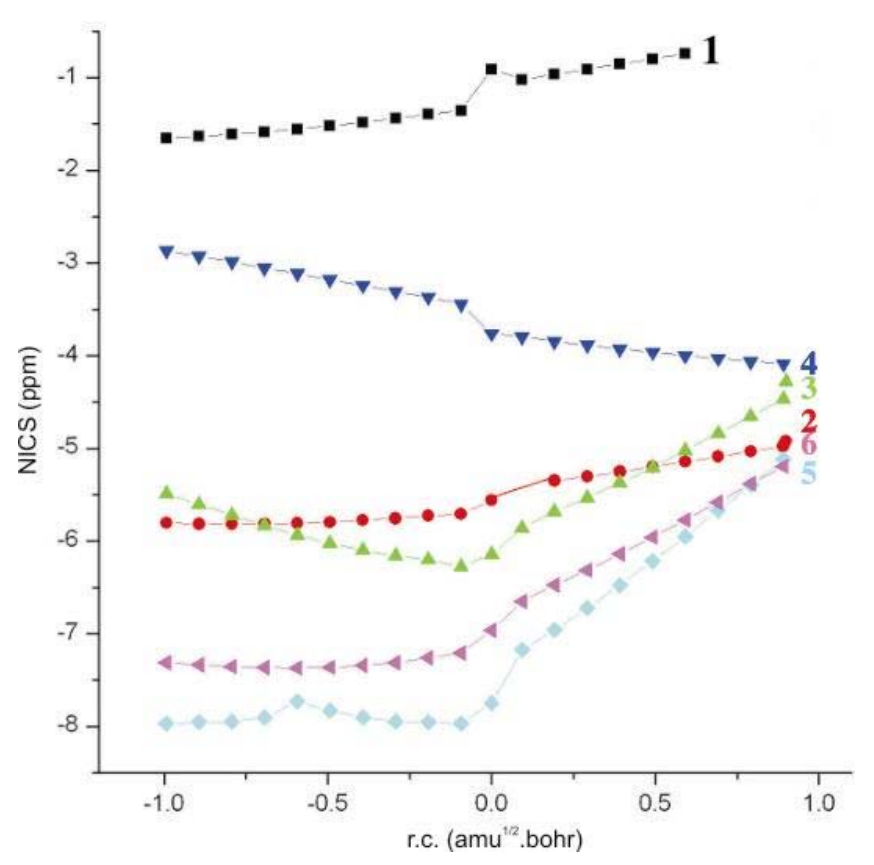

Figure 4. Variation of NICS (0) along the reaction coordinate.

is indicative of pericyclic character of the reaction. Reaction 4 does not show up minimum near the TS in the profile, hence it is classified as a borderline. NICS (0) profile show that aromatic character of the species has gradually increased from reaction 1-6 and this reveals the increasing pericyclic character down the series. Further fluorine substitution decreases the aromaticity of the species along the reaction coordinate for reactions 4 and 6 while it increases the aromatic character for the reaction 2 .

\subsection{Natural bond order analysis}

Effect of fluorine has been discussed by monitoring the Wiberg bond orders, second-order perturbation energy analysis and NLMO interactions for the reactions 1-6. Table 2 lists the Wiberg bond orders of selected bonds. It is seen that presence of fluorine at C6 has increased the bond order of the forming bond $(\mathrm{O} 1-\mathrm{C} 2)$ at the TS but the increase is quite large for pericyclic/borderline reactions $(3,4,5$ and 6$)$ than for pseudopericyclic reaction (2).

NLMO bond orders in table 3 show that in reactions 1 and 2, the main contribution to the $\mathrm{O} 1-\mathrm{C} 2$ bond is mainly from LP Ol characteristic of pseudeopericyclic reactions. In reactions 3 and 5, the lone pair participation to the forming/cleaving $\mathrm{Ol}-$ $\mathrm{C} 2$ bond is very little. So these reactions are pericyclic in nature. In reaction 4, major contributions comes from $\sigma \mathrm{O} 1-\mathrm{C} 2$ bond but not from LP O1; this signifies that $\mathrm{O} 1-\mathrm{C} 2$ bond has not cleaved in TS4 and hence makes a large bond order contribution. This shows the reactant like nature of the TS4 and explains the moderate activation barrier $\left(\Delta G^{\ddagger}=\right.$ 
Table 4. Prominent second order perturbations of interactions in the TS.

\begin{tabular}{|c|c|c|c|c|c|c|}
\hline $\begin{array}{l}\text { Donor-acceptor } \\
\text { interactions }\end{array}$ & TS 2 & TS 3 & TS 4 & TS 5 & TS 6 & Cyclohexadiene \\
\hline$\pi \mathrm{C} 2-\mathrm{C} 3-\pi * \mathrm{C} 4-\mathrm{C} 5$ & $65 \cdot 10$ & $92 \cdot 56$ & - & $76 \cdot 16$ & - & $33 \cdot 08$ \\
\hline$\pi \mathrm{O} 1-\mathrm{C} 6-\pi * \mathrm{C} 4-\mathrm{C} 5$ & $3 \cdot 47$ & $3 \cdot 81$ & - & - & - & $33 \cdot 08$ \\
\hline$\pi \mathrm{C} 4-\mathrm{C} 5-\pi * \mathrm{C} 2-\mathrm{C} 3$ & $9 \cdot 84$ & $10 \cdot 85$ & - & $12 \cdot 58$ & - & $38 \cdot 12$ \\
\hline$\pi \mathrm{C} 2-\mathrm{C} 3-\pi * \mathrm{O} 1-\mathrm{C} 6$ & $1 \cdot 33$ & $5 \cdot 48$ & - & - & - & $26 \cdot 45$ \\
\hline$\pi \mathrm{O} 1-\mathrm{C} 6-\pi^{*} \mathrm{C} 2-\mathrm{C} 3$ & $2 \cdot 09$ & 9.79 & - & $16 \cdot 07$ & - & $26 \cdot 45$ \\
\hline$\pi \mathrm{C} 4-\mathrm{C} 5-\pi * \mathrm{C} 6-\mathrm{O} 1$ & $71 \cdot 49$ & 88.00 & - & $77 \cdot 29$ & - & $38 \cdot 12$ \\
\hline$\pi \mathrm{C} 5-\mathrm{C} 6-\pi * \mathrm{C} 3-\mathrm{C} 4$ & - & - & $69 \cdot 73$ & - & 78.97 & - \\
\hline $\mathrm{LP}(2) \mathrm{O} 8-\pi * \mathrm{C} 2-\mathrm{C} 3$ & $182 \cdot 45$ & $53 \cdot 63$ & - & - & - & - \\
\hline $\mathrm{LP}(2) \mathrm{O} 1-\pi * \mathrm{C} 2-\mathrm{O} 8$ & $71 \cdot 56$ & - & - & - & - & - \\
\hline $\mathrm{LP}(3) \mathrm{F} 7-\pi * \mathrm{C} 6-\mathrm{O} 1$ & $38 \cdot 50$ & - & - & - & - & - \\
\hline $\mathrm{LP}(3) \mathrm{F} 7-\pi * \mathrm{C} 5-\mathrm{C} 6$ & - & - & $31 \cdot 37$ & - & 31.72 & - \\
\hline $\mathrm{LP}(2) \mathrm{O} 1-\pi * \mathrm{C} 5-\mathrm{C} 6$ & - & $13 \cdot 05$ & $65 \cdot 10$ & - & 58.67 & - \\
\hline $\mathrm{LP}(2) \mathrm{O} 1-\pi * \mathrm{C} 2-\mathrm{C} 3$ & & $53 \cdot 58$ & - & $52 \cdot 41$ & - & - \\
\hline
\end{tabular}

Table 5. Angular and azimuthal coordinates of the LP(2) of $\mathrm{O} 1$ and $\mathrm{O} 8$ along the reaction coordinate of ERO of reaction 2 obtained from NHO directionality analysis.

\begin{tabular}{|c|c|c|c|c|}
\hline \multirow[b]{2}{*}{ r.c. $(\mathrm{amu}) 1 / 2 \mathrm{Bohr} \times 0 \cdot 1$} & \multicolumn{2}{|c|}{$\begin{array}{c}\mathrm{LP}(2) \mathrm{O} 1 \\
\text { NHO directionality }\end{array}$} & \multicolumn{2}{|c|}{$\begin{array}{c}\mathrm{LP}(2) \mathrm{O} 8 \\
\text { NHO directionality }\end{array}$} \\
\hline & $\vartheta$ & $\phi$ & $\vartheta$ & $\phi$ \\
\hline$-1 \cdot 0$ & $90 \cdot 0$ & $308 \cdot 2$ & $0 \cdot 0$ & $0 \cdot 0$ \\
\hline$-0 \cdot 9$ & $90 \cdot 0$ & $308 \cdot 3$ & $0 \cdot 0$ & $0 \cdot 0$ \\
\hline$-0 \cdot 8$ & $90 \cdot 0$ & $308 \cdot 3$ & $0 \cdot 0$ & $0 \cdot 0$ \\
\hline-0.7 & - & - & $90 \cdot 0$ & $318 \cdot 3$ \\
\hline$-0 \cdot 6$ & - & - & $90 \cdot 0$ & $318 \cdot 3$ \\
\hline$-0 \cdot 5$ & - & - & $90 \cdot 0$ & $317 \cdot 2$ \\
\hline$-0 \cdot 4$ & - & - & $90 \cdot 0$ & $317 \cdot 2$ \\
\hline$-0 \cdot 3$ & - & - & $90 \cdot 0$ & $316 \cdot 1$ \\
\hline$-0 \cdot 2$ & - & - & $90 \cdot 0$ & $315 \cdot 5$ \\
\hline$-0 \cdot 1$ & - & - & $90 \cdot 0$ & $318 \cdot 3$ \\
\hline $0 \cdot 0$ & $0 \cdot 0$ & $0 \cdot 0$ & $90 \cdot 0$ & $312 \cdot 4$ \\
\hline $0 \cdot 1$ & $0 \cdot 0$ & $0 \cdot 0$ & $90 \cdot 0$ & $309 \cdot 9$ \\
\hline $0 \cdot 2$ & $0 \cdot 0$ & $0 \cdot 0$ & $90 \cdot 0$ & $309 \cdot 4$ \\
\hline $0 \cdot 3$ & $0 \cdot 0$ & $0 \cdot 0$ & $90 \cdot 0$ & $308 \cdot 8$ \\
\hline $0 \cdot 4$ & $0 \cdot 0$ & $0 \cdot 0$ & $90 \cdot 0$ & $308 \cdot 2$ \\
\hline 0.5 & $0 \cdot 0$ & $0 \cdot 0$ & $90 \cdot 0$ & $307 \cdot 6$ \\
\hline 0.6 & $0 \cdot 0$ & $0 \cdot 0$ & $90 \cdot 0$ & $307 \cdot 0$ \\
\hline 0.7 & $0 \cdot 0$ & $0 \cdot 0$ & $90 \cdot 0$ & $306 \cdot 5$ \\
\hline 0.8 & $0 \cdot 0$ & $0 \cdot 0$ & $90 \cdot 0$ & $306 \cdot 0$ \\
\hline $0 \cdot 9$ & $0 \cdot 0$ & $0 \cdot 0$ & $90 \cdot 0$ & 305.5 \\
\hline 1.0 & $0 \cdot 0$ & $0 \cdot 0$ & $90 \cdot 0$ & $305 \cdot 0$ \\
\hline
\end{tabular}

$14.96 \mathrm{kcal} / \mathrm{mol}$ ). This is in accordance with the Hammond's postulate which states that exothermic reaction has a reactant like TS and endothermic reaction has a product like TS.

Second order perturbation energy analysis results for the electrocyclic TSs are presented in table 4 .
One can see that fluorine has modified the perturbations greatly in processes involving pyranol and pyran and not much in pyrone. The effect is such that the perturbations which appeared in reactions 3 and 5 have totally disappeared on fluorine substitution (reactions 4 and 6) and new intense perturba- 
tions have arisen. It will be fruitful to compare every case with a typical pericyclic reaction of cyclohexadiene. This will help in the understanding the effect of heteroatom, particularly the fluorine atom, on altering the pericyclic/pseudopericyclic character of the reactions considered. Pseudopericyclic reactions (reaction 1 and 2) differ from the reaction of cyclohexadiene in that they have very large $\mathrm{LP}-\Pi^{*}$ interactions and fluorine has decreased these $\mathrm{LP}-\Pi^{*}$ interactions.

\subsection{Orbital disconnections}

Orbital disconnections where a lone pair and bond pair exchange their roles are the prominent features occurring in pseudopericyclic reactions and distinguish them from pericyclic reactions. ${ }^{8,9-12}$ These disconnections bring discontinuities in the cyclic overlap of orbitals at the TS and there is no aromatic enhancement in the transition state. Rodríguez et $a l^{28}$ reported that the disconnections occurred at 0.04 $(\mathrm{amu})^{1 / 2}$. Bohr for the ERC of 5-oxo-pentadienal to 2P. His conclusion was based on the angular and azimuthal angles available from NHO directionality for NBO analysis. With the help of the angular and azimuthal angle from NHO directionality of every point along the reaction coordinate of reaction 2 (table 5) it is evident that the disconnection now occurs at $0.07(\mathrm{amu})^{1 / 2}$. Bohr. At this point LPO1 changes $\theta$ from 0 to 90 and that of 07 changes it from 90 to 0 . This shows that fluorine has delayed the point of disconnection in this pseudopericyclic reaction 2 . There are no disconnections in reactions $3,4,5$ and 6 as there is continual rotation of LP of $\mathrm{O} 1$ and 07 and therefore they are not presented here.

The orbital disconnection can be explained by propargyl-allenyl form exhibited by reaction 2 along the reaction coordinate. The NHO analysis indicates that there are two disconnections. They can be explained as follows: At $0.07(\mathrm{amu})^{1 / 2}$. Bohr lone pair of $\mathrm{O} 8$ becomes $\mathrm{C} 2-\mathrm{O} 8$ bond pair and exists in the propargyl form as shown below and due to this, a temporary lone pair is generated at $\mathrm{C} 4$. At the same time the lone pair of $\mathrm{O} 1$ becomes a bond pair at $\mathrm{O} 1-\mathrm{C} 6$ bond and the bond pair of $\mathrm{C} 2-\mathrm{O} 1$ bond becomes the lone pair of $\mathrm{O} 1$. Because of the formation of propargyl form the bond pair at $\mathrm{C} 2-\mathrm{O} 8$ is not immediately released as lone pair of 08 till TS is reached. At the TS, the propargyl form returns to allenyl form leaving one of the $\mathrm{O} 8-\mathrm{C} 2$ bond pair as lone pair.

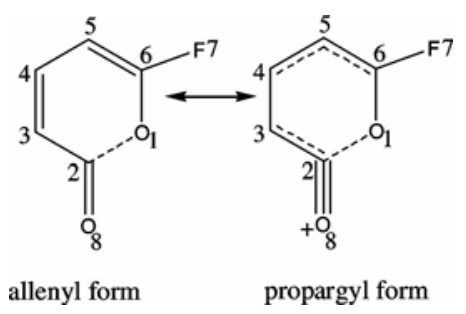

\subsection{Bond critical property analysis}

It is well-known that $\nabla^{2} \rho(r)$ can indicate local depletion or accumulation of electrons. ${ }^{26}$ If $\nabla^{2} \rho(r)<0$ then there is a shared interaction associated with the covalent and polar bonds and when $\nabla^{2} \rho(r)>0$, there is a closed shell interaction associated with ionic, hydrogen bonds and van der Waals complexes. Table 6 presents the BCP properties of every bond in the all reactions 1-6 under study. $\nabla^{2} \rho(r)$ of $\mathrm{O} 1-\mathrm{C} 2<0$ initially in the reactant corresponds to sharing interaction but in their TSs one can find that electron density at BCP has been reduced greatly and $\nabla^{2} \rho(r)>0$, showing a closed shell interaction (ionic interaction). It is interesting to compare this with the $\nabla^{2} \rho(r)$ value of the same cleaving bond in cyclohexadiene (during ERO of cyclohexadiene to hexatriene). It is found that $\nabla^{2} \rho(r)$ for this bond is 0.0396 . The large positive $\nabla^{2} \rho(r)$ of $\mathrm{O} 1-\mathrm{C} 2$ bond in both reactions 1 and 2 indicates ionic interactions and this is consistent with the already known fact that pseudopericyclic ring opening is a nucleophilic attack on electrophilic centre.

TSs of reactions 3, 4, 5 and 6 have almost similar $\nabla^{2} \rho(r)$ values which are larger than that for cyclohexadiene TS. This establishes that again the hetero atom with LP on it is ready for nucleophilic attack. But here no terminal orthogonal array of orbitals are available for disconnections. So the reaction is pericyclic and not pseudopericyclic. This is in agreement with proposition that the involvement of LP of hetero atom may push the pericyclic reaction to become more pseudopericyclic. ${ }^{28}$

\subsection{Conclusions}

Energetics, magnetic property, NBO and bond critical property analyses clearly indicate reactions 1 and 2 as pseudopericyclic and reactions 5 and 6 as pericyclic in character. Reactions 3 and 4 are found to be borderline cases and in that reaction 3 lie on the pericyclic side. Substitution of fluorine on the $6^{\text {th }}$ 
position of pyrone, pyranol and pyran favour ERO reaction kinetically and thermodynamically. Both $\Delta \chi_{\text {aniso }}$ and NICS (0) profiles show that substitution of fluorine has decreased the aromaticity of the species along the reaction coordinate especially in the reactions 4 and 6 . Fluorine substitution does not alter the aromatic enhancement for reaction 2. But substitution of fluorine diminishes the pericyclic character of reaction 4 and makes it a borderline case. The fluorine affects the pseudoelectrocyclic reactions by reducing the LP contribution to the

Table 6. Bond critical properties of some selected bonds at MP2/6-31G $(d)$ level.

\begin{tabular}{|c|c|c|c|c|c|}
\hline & & \multicolumn{2}{|r|}{1} & \multicolumn{2}{|c|}{2} \\
\hline & & $\rho(r)$ & $\nabla 2 \rho(r)$ & $\rho(r)$ & $\nabla 2 \rho(r)$ \\
\hline \multirow[t]{2}{*}{$\mathrm{O} 1-\mathrm{C} 2$} & $\mathrm{R}$ & 0.2530 & -0.2690 & $0 \cdot 2270$ & -0.2536 \\
\hline & $\mathrm{TS}$ & 0.0609 & $0 \cdot 1525$ & 0.0599 & $0 \cdot 1505$ \\
\hline \multirow[t]{2}{*}{$\mathrm{C} 2-\mathrm{C} 3$} & $\mathrm{R}$ & 0.2995 & -0.9371 & $0 \cdot 3008$ & -0.9536 \\
\hline & $\mathrm{TS}$ & 0.3105 & -0.5132 & $0 \cdot 3050$ & -0.5493 \\
\hline \multirow[t]{2}{*}{$\mathrm{C} 3-\mathrm{C} 4$} & $\mathrm{R}$ & 0.3392 & -1.0500 & 0.3374 & $-0 \cdot 1043$ \\
\hline & $\mathrm{TS}$ & $0 \cdot 3089$ & -0.9193 & $0 \cdot 3106$ & -0.9295 \\
\hline \multirow[t]{2}{*}{$\mathrm{C} 4-\mathrm{C} 5$} & $\mathrm{R}$ & 0.3025 & -0.9148 & 0.3027 & -0.9104 \\
\hline & $\mathrm{TS}$ & 0.3371 & $-0 \cdot 1089$ & 0.3290 & $-1 \cdot 0230$ \\
\hline \multirow[t]{2}{*}{ C5-C6 } & $\mathrm{R}$ & 0.3449 & $-1 \cdot 1240$ & 0.3394 & -0.9966 \\
\hline & $\mathrm{TS}$ & 0.3173 & $-0 \cdot 1006$ & 0.3174 & $-1 \cdot 088$ \\
\hline \multirow[t]{3}{*}{ C6-O1 } & $\mathrm{R}$ & $0 \cdot 2854$ & 0.0338 & $0 \cdot 3190$ & 0.0799 \\
\hline & $\mathrm{TS}$ & $0 \cdot 2929$ & $0 \cdot 3745$ & $0 \cdot 3985$ & $-0 \cdot 1188$ \\
\hline & & \multicolumn{2}{|r|}{5} & \multicolumn{2}{|c|}{4} \\
\hline \multirow[t]{2}{*}{$\mathrm{O} 1-\mathrm{C} 2$} & $\mathrm{R}$ & $0 \cdot 2421$ & $-0 \cdot 2711$ & $0 \cdot 2432$ & -0.4772 \\
\hline & $\mathrm{TS}$ & 0.0660 & $0 \cdot 1456$ & 0.0862 & $0 \cdot 1493$ \\
\hline \multirow[t]{2}{*}{$\mathrm{C} 2-\mathrm{C} 3$} & $\mathrm{R}$ & 0.2848 & -0.8529 & 0.2707 & -0.6985 \\
\hline & $\mathrm{TS}$ & 0.3241 & $-1 \cdot 1110$ & $0 \cdot 3078$ & -0.8791 \\
\hline \multirow[t]{2}{*}{$\mathrm{C} 3-\mathrm{C} 4$} & $\mathrm{R}$ & $0 \cdot 3440$ & -1.0540 & 0.3384 & -0.9584 \\
\hline & $\mathrm{TS}$ & 0.3223 & -0.9833 & 0.3189 & -0.8737 \\
\hline \multirow[t]{2}{*}{$\mathrm{C} 4-\mathrm{C} 5$} & $\mathrm{R}$ & 0.2927 & -0.8637 & $0 \cdot 2847$ & -0.7334 \\
\hline & $\mathrm{TS}$ & 0.3116 & -0.9241 & 0.2989 & -0.7802 \\
\hline \multirow[t]{2}{*}{$\mathrm{C} 5-\mathrm{C} 6$} & $\mathrm{R}$ & $0 \cdot 3468$ & $-1 \cdot 1150$ & $0 \cdot 3266$ & -0.9469 \\
\hline & $\mathrm{TS}$ & 0.3107 & -0.9415 & $0 \cdot 3101$ & -0.8739 \\
\hline \multirow[t]{3}{*}{$\mathrm{C} 6-\mathrm{O} 1$} & $\mathrm{R}$ & 0.2828 & -0.0686 & $0 \cdot 2930$ & -0.6006 \\
\hline & $\mathrm{TS}$ & $0 \cdot 3608$ & -0.0272 & 0.3712 & $-0 \cdot 2909$ \\
\hline & & \multicolumn{2}{|r|}{5} & \multicolumn{2}{|c|}{6} \\
\hline \multirow[t]{2}{*}{$\mathrm{O} 1-\mathrm{C} 2$} & $\mathrm{R}$ & 0.2349 & $-0 \cdot 1583$ & $0 \cdot 2243$ & -0.0522 \\
\hline & $\mathrm{TS}$ & $0 \cdot 0703$ & $0 \cdot 1450$ & 0.0820 & $0 \cdot 1400$ \\
\hline \multirow[t]{2}{*}{$\mathrm{C} 2-\mathrm{C} 3$} & $\mathrm{R}$ & 0.2747 & -0.7828 & 0.2742 & -0.7807 \\
\hline & $\mathrm{TS}$ & $0 \cdot 3243$ & $-1 \cdot 0300$ & $0 \cdot 3189$ & $-1 \cdot 0240$ \\
\hline \multirow[t]{2}{*}{ C3-C4 } & $\mathrm{R}$ & 0.3450 & $-1 \cdot 0600$ & $0 \cdot 3449$ & $-1 \cdot 0580$ \\
\hline & $\mathrm{TS}$ & 0.3185 & -0.9757 & 0.3213 & -0.9825 \\
\hline \multirow[t]{2}{*}{$\mathrm{C} 4-\mathrm{C} 5$} & $\mathrm{R}$ & 0.2883 & -0.8373 & 0.2869 & -0.8262 \\
\hline & $\mathrm{TS}$ & 0.3144 & -0.9301 & $0 \cdot 3133$ & -0.9321 \\
\hline \multirow[t]{2}{*}{ C5-C6 } & $\mathrm{R}$ & $0 \cdot 3445$ & -1.0970 & $0 \cdot 3413$ & $-0 \cdot 1014$ \\
\hline & $\mathrm{TS}$ & $0 \cdot 3068$ & -0.9243 & $0 \cdot 3113$ & -1.034 \\
\hline \multirow[t]{2}{*}{$\mathrm{C} 6-\mathrm{O} 1$} & $\mathrm{R}$ & $0 \cdot 2888$ & $-0 \cdot 1358$ & $0 \cdot 3167$ & $-0 \cdot 3984$ \\
\hline & $\mathrm{TS}$ & 0.3627 & 0.0251 & $0 \cdot 3820$ & $-0 \cdot 2514$ \\
\hline
\end{tabular}

cleaving bond at the TS. The effect of fluorine is quite obvious from orbital interactions of reactions 4 and 6 and reactions 3 and 5. Orbital disconnections are delayed in reaction 2 due to fluorine substitution and propargyl-allenyl forms explain the switching over clearly. The large positive laplacian of electron density at the cleaving bond indicates the nucleophilic attack on electrophilic centre of the pseudopericyclic nature of the reaction 2. In conclusion, fluorine substitution gradually increases the pseudopericyclic character in the reactions considered here through lone pair participation in the orbital overlap.

\section{Acknowledgements}

We thank University Grants Commission (UGC), India for financial support in the form of major research grant (F. No. 33-256/2007. SR and PV thanks Indian National Science Academy (INSA) for the INSA-Royal Society Visiting Fellowship for the year 2006-2007.

\section{References}

1. Lemal D 1976 J. Am. Chem. Soc. 984325

2. Birney D M and Wagenseller P E $1994 \mathrm{~J}$. Am. Chem. Soc. 1166262

3. Birney D M, Ham S and Unruh G R $1997 \mathrm{~J} . \mathrm{Am}$. Chem. Soc. 1194509

4. (a) Birney D M, Xu X and Ham S 1999 Angew. Chem., Int. Ed. 38 189; (b) Birney D M $2000 \mathrm{~J}$. Am. Chem. Soc. 12210917

5. Shumway W W, Dalley N K and Birney D M $2001 \mathrm{~J}$. Org. Chem. 665832

6. Zhou C and Birney D M 2002 J. Am. Chem. Soc. 124 5237

7. Herges R, Jiao H and Schleyer P v R 1994 Angew. Chem., Int. Ed. Engl. 331376

8. Schleyer P v R, Maerker C, Dransfeld A, Jiao H and van Eikema Hommes N J R $1996 \mathrm{~J}$. Am. Chem. Soc. 1186317

9. Herges R and Geuenich D 2001 J. Phys. Chem A 105 3214

10. Herges R and Papafilippopoulos A 2001 Angew. Chem., Int. Ed. Engl. 404671

11. Kimball D B, Weakley T J R, Herges R and Haley M M 2002 J. Am. Chem. Soc. 12413463

12. Geuenich D, Hess K, Köhler F and Herges R 2005 Chem. Rev. 1053758

13. Rodríguez-Otero J and Cabaleiro-Lago E M 2002 Angew. Chem., Int. Ed. 411147

14. Rodríguez-Otero J and Cabaleiro-Lago E M 2002 Chem. Eur. J. 200391837

15. Cabaleiro-Lago E M, Rodríguez-Otero J and HermidaRamón J M 2003 J. Phys. Chem A 1074962 
16. Rodríguez-Otero J, Cabaleiro-Lago E M, HermidaRamón J M and Peña-Gallego A $2003 \mathrm{~J}$. Org. Chem. 688823

17. Montero-Campillo M M, Rodríguez-Otero J and Cabaleiro-Lago E M 2004 J. Phys. Chem A 108 8373

18. Cabaleiro-Lago E M, Rodríguez-Otero J, VarelaVarela S M, Peña-Gallego A and Hermida-Ramón J 2005 J. Org. Chem. 70392

19. Cabaleiro-Lago E M, Rodríguez-Otero J, GonzálezLópez I, Peña-Gallego and Hermida-Ramón J $2005 \mathrm{~J}$. Phys. Chem A 1095636

20. López C S, Faza O N, Cossío F P, Cork D M and de Lera A R 2005 Chem. Eur. J. 2005111734

21. Savin A, Nesper R, Wengert S and Fässler T F 1997 Angew. Chem., Int. Ed. Engl. 361808

22. Chamorro E 2003 J. Chem. Phys. 1188687

23. Chamorro E and Notario R 2004 J. Phys. Chem A 108 4099

24. Chamorro E and Notario R 2005 J. Phys. Chem A 109 7594; Chamorro E and Notario R 2005 J. Phys. Chem A 1094352

25. Maito E, Poater J, Duran M and Sola M 2006 Chem. Phys. Chem. 7 111-113

26. Calvo-Losada S and Quirante Sánchez J J $2008 \mathrm{~J}$. Phys. Chem A 1128164

27. Birney D M 1996 J. Org. Chem. 61243

28. Rodríguez-Otero J and Cabaleiro-Lago E M 2003 Chem. Eur. J. 91837

29. Akilandeswari L and Venuvanalingam P $2007 \mathrm{~J}$. Theor. Comp. Chem. 6233

30. Akilandeswari L $2008 \mathrm{Ph} \mathrm{D}$ Thesis, Bharathidasan University

31. Karney W L and Borden W T $1997 \mathrm{~J}$. Am. Chem. Soc. 1193347

32. Borden W T 1998 Chem. Commun. 1919
33. Barone V and Adamo C 1996 J. Chem. Phys. 10511007

34. Reva I, Breda S, Roseiro T, Eusébio S and Fausto R 2005 J. Org. Chem. 707701

35. Frisch M J, Trucks G W, Schlegel H B, Scuseria G E, Robb M A, Cheeseman J R, Zakrzewski V G, Montgomery J, Stratmann R E, Burant J C, pprich, Millam J M, Daniels A D, Kudin K N, Strain M C, Farkas O, Tomasi J, Barone V, Cossi M, Cammi R, Mennucci B, Pomelli C, Adamo C, Clifford S, Ochterski J, Petersson G A, Ayala P Y, Cui Q, Morokuma K, Malick D K, Rabuck A D, Raghavachari K, Foresman J B, Cioslowski J, Ortiz J V, Baboul A G, Stefanov B B, Liu G, Liashenko A, Piskorz P, Komaromi I, Gomperts R, Martin R L, Fox D J, Keith T, AlLaham M A, Peng C Y, Nanayakkara A, Gonzalez C, Challacombe M, Gill P M W, Johnson B G, Chen W, Wong M W, Andres J L, Head-Gordon M, Replogle E S and Pople J A 1998 Gaussian 98, Revision A9, Gaussian, Inc: Pittsburgh, PA

36. Foster J P and Weinhold F $1980 \mathrm{~J}$. Am. Chem. Soc. 1027211

37. Reed A D, Curtiss L A and Weinhold F 1988 Chem. Rev. 88899

38. Glendening E D, Reed A E, Carpenter J E and Weinhold F 1988 NBO 3.1 Program Manual

39. Fukui K 1981 Acc. Chem. Res. 14363

40. Gonzalez C and Schlegel H B 1989 J. Chem. Phys. 902154

41. Gonzalez C and Schlegel H B $1990 \mathrm{~J}$. Phys. Chem. 945223

42. Wolinski K, Hilton J F and Pulay $\mathrm{P} 1990 \mathrm{~J}$. Am. Chem. Soc. 1128251

43. Keith T A and Bader R F W 1993 Chem. Phys. Lett. 210223

44. Keith T A and Bader R F W 1992 Chem. Phys. Lett. 1941 